\title{
Supplementation with an Antioxidant Rich Oil Does Not Influence Blood Lactate, Rate of Perceived Exertion and Muscle Soreness after Resistance Exercise
}

\author{
Maurilio T. Dutra ${ }^{1^{*}}$, Mateus M. Leite ${ }^{2}$, Arthur César M. Santos ${ }^{2}$, Lucas C. C. Nemer ${ }^{2}$, Matheus \\ B. S. Barros ${ }^{2}$, Renata A. E. Dantas ${ }^{2}$, Márcio R. Mota ${ }^{2,3,4}$

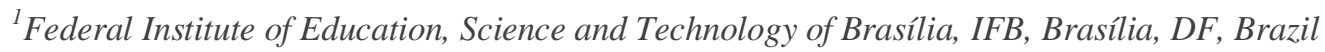 \\ ${ }^{2}$ University Center of Brasília, UniCEUB, Brasília, DF, Brazil \\ ${ }^{3}$ Anápolis University Center, UniEVANGÉLICA, Anápolis, GO, Brazil \\ ${ }^{4}$ Projeção University Center, UniPROJEÇÃO, Brasília, DF, Brazil
}

*Corresponding Author: Maurilio T. Dutra, Federal Institute of Education, Science and Technology of Brasília, IFB, Brasília, DF, Brazil

\begin{abstract}
Pequi (Caryocar brasiliense) is a fruit from Brazil with antioxidant properties. Previous research suggested that it could be a candidate for sports ergogenic aid. However, little is known about pequi supplementation and sports performance. Aim: to analyze the effect of pequi oil supplementation on blood lactate, rate of perceived exertion and muscle soreness after a resistance exercise session. Twelve men $\left(21.1 \pm 2.6\right.$ years, $\left.77.0 \pm 10.5 \mathrm{~kg}, 24.3 \pm 1.9 \mathrm{Kg} / \mathrm{m}^{2}\right)$ underwent pequi supplementation for 14 days. Before and after supplementation they performed an exercise session in the chest press. Lactate, rate of perceived exertion and muscle soreness were measured. No significant difference was found after the supplementation $(P>.05)$.Pequi oil supplementation has no influence on blood lactate concentration, rate of perceived exertion and muscle soreness during resistance exercise.
\end{abstract}

Keywords: Pequi, caryocar brasiliense, lactate, perceived exertion, muscle soreness, resistance exercise

Abbreviations: DNA: deoxyribonucleic acid, OMNI-RES: OMNI-Resistance Exercise Scale, RM: Repetition maximum, VAS: Visual analog scale

\section{INTRODUCTION}

Pequi (Caryocar brasiliense) is a very common fruit of the Brazilian cerrado. It is largely consumed by local residents and its pulp contains natural antioxidants, such as carotenoids (i.e. $\alpha$ and $\beta$ carotene) and phenolic acids. Concentration of phenolic acids in pequi pulp is higher (i.e. $209 \mathrm{mg} / 100 \mathrm{~g}$ ) than many other fruits such as strawberry (i.e. $132,1 \mathrm{mg} / 100 \mathrm{~g}$ ) and pineapple (i.e. $21,7 \mathrm{mg} / 100 \mathrm{~g}$ ) [1]. Thus, pequi has an elevated antioxidant capacity. So, supplementation with pequi oil became a target of some researchers in the past 10 years.

Of note, findings of previous research showed that supplementation with pequi oil (i.e. $400 \mathrm{mg} / \mathrm{day}$ ) can attenuate cardiovascular inflammation in Systemic lupus erythematosus patients [2]. Moreover, it has been shown that pequi oil supplementation (i.e. $400 \mathrm{mg} /$ day) for only 14 days reduces plasma lipid peroxidation, inflammatory markers and DNA damage related to exercise in runners[3,4].

Based on that, it could be suggested that pequi oil supplementation can reduce exercise related damage. So, this strategy started to be seen as a candidate for sports ergogenic aid. However, literature still lacks research on this topic, especially with regard to the effect of pequi supplementation in a context of resistance exercise.

Thus, the purpose of this pre-experimental investigation was to analyze the effect of pequi oil supplementation on blood lactate, rate of perceived exertion and rate of perceived pain after a single bout of resistance exercise before and after 14 days of pequi supplementation. 


\section{MATERIALS AND MethodS}

This is a pre-experimental protocol. Dependent variables were assessed before and after 14 days of pequi oil supplementation. Twelve healthy men between 18 and 30 years old with previous experience in ST volunteered to participate. All procedures were conducted according to the Helsinki Declaration and the protocol was approved by the Institutional Review Board, process number 2.954.476/2018.

Repetition maximum (1RM) test at the bench press was conducted before and after 14 days of supplementation adopting previous recommendations [5]. Moreover, before and after supplementation participants performed a resistance exercise session at the bench press as follows: warm-up set of 15 repetitions at 30\% 1RM followed by 4 sets of 4 to 6 repetitions at $80 \% 1 \mathrm{RM}$ with 1 minute interval between sets. Exercise cadence was 2 seconds concentric, and 4 seconds eccentric phase.

Blood lactate was collected at the end of the fourth exercise set and 15 minutes after the end of the exercise at the distal phalanx of the ring finger and immediately analyzed using a portable device (Accutrend Plus ${ }^{\circledR}$ ). At the end of each set, rate of perceived exertion was collected using the OMNIRES scale [6]. The level of muscle soreness was assessed $24 \mathrm{~h}$ after the exercise session using a visual analog scale (VAS) in which " 0 " indicated no pain and "10" represented extreme pain. Collection of this variable was performed through palpation according to previous literature [7].

Participants received a pack containing 14 pequi oil capsules. Each capsule contained $400 \mathrm{mg}$ of pequi oil and should be consumed one per day. Subjects were oriented to avoid eating pequi and drinking antioxidant beverages during the supplementation. Participants were also oriented to maintain their exercise routines during the supplementation period. Data normality was assessed using the Kolmogorov-Smirnov test and Paired T-test was used to compare dependent variables before and after supplementation. Significance level at $P \leq .05$ was adopted.

\section{RESULTS AND DISCUSSION}

Descriptive characteristics of the sample are presented in table 1. All participants were young healthy college students with previous experience in resistance exercise.

Table1: Descriptive characteristics of the sample

\begin{tabular}{|l|l|}
\hline \multicolumn{1}{|c|}{ Variable } & \multicolumn{1}{c|}{ Mean \pm SD } \\
\hline Age $($ years) & $21.1 \pm 2.6$ \\
\hline Body mass $(\mathrm{kg})$ & $77.0 \pm 10.5$ \\
\hline Heigth $(\mathrm{m})$ & $1.78 \pm 0.11$ \\
\hline BMI $\left(\mathrm{Kg} / \mathrm{m}^{2}\right)$ & $24.3 \pm 1.9$ \\
\hline
\end{tabular}

Note: BMI body mass index. RM repetition maximum.

Main results of this short report are presented in Table 2. Muscle strength improved significantly after supplementation. However, no significant difference was observer in blood lactate, rate of perceived exertion (mean of the four sets) and muscle soreness after the supplementation when compared to before.

Table2: Dependent variables before and after pequi supplementation (Mean $\pm S D$ )

\begin{tabular}{|l|l|l|}
\hline \multicolumn{1}{|c|}{ Variable } & \multicolumn{1}{c|}{ Before } & \multicolumn{1}{c|}{ After } \\
\hline 1 RM Strength (Kg) & $75.1 \pm 11.1$ & $77.0 \pm 11.0^{*}$ \\
\hline Lactate immediately after (mmol/L) & $6.9 \pm 1.5$ & $7.2 \pm 1.3$ \\
\hline Lactate 15min after (mmol/L) & $4.3 \pm 0.76^{\#}$ & $4.5 \pm 1.3^{\#}$ \\
\hline Perceived Exertion (OMNI-RES) & $8.1 \pm 1.1$ & $8.2 \pm 0.76$ \\
\hline 24h perceived soreness (VAS) & $7.5 \pm 1.2$ & $6.5 \pm 1.7$ \\
\hline
\end{tabular}

Notes: $* P<.05$ vs before. \# $P<.01$ vs immediately after. VAS: visual analog scale.

The aim of this report was to analyze the effect of pequi oil supplementation on blood lactate, rate of perceived exertion and muscle soreness after a resistance exercise session. No significant difference was observed regarding these variables after supplementation when compared to before. Lactate concentration was significantly lower 15 minutes after exercise at both sessions compared to immediately after exercise, however with no difference between before and after supplementation. However, bench press maximum strength was found to be increased after supplementation with pequi oil. 
Pequi supplementation was previously found to reduce inflammatory markers, lipid peroxidation and DNA damage of marathon runners after 14 days of supplementation with the same dosage of the present study [3,4]. So, it could be expected that supplementation would reduce resistance exercise damage and, as a consequence, reduce blood lactate accumulation, rate of perceived exertion and muscle soreness.

Hence, the lack of significant differences in lactate, rate of perceived exertion and muscle soreness assessments indicate that pequi oil supplementation may have a different (no?) effect regarding resistance exercise protocols. The high intensity exercise protocol adopted in the present report was intended to induce muscle damage, as it is commonly reported in resistance exercise [8]. However, some factor has to be considered to explain these results.

Firstly, even though the present exercise protocol was of high intensity, total exercise volume was low because only one exercise was performed. Probably, a higher volume resistance exercise session would be needed to evoke a more pronounced acute physiological response that would make evident a protective effect (if some) of the supplementation. Secondly, participants were resistance trained, and it is known that inflammation and exercise induced muscle damage are of a less magnitude in this situation compared to unaccustomed exercise $[9,10]$. Of note, participants did their habitual resistance training sessions during the supplementation period. As we do not have a control group, the strength gain observed after the supplementation is probably relate to participants habitual training routine.

Limitations are recognized that preclude further discussion. Main limitation is the lack of a control group that could provide more light to the discussion. Moreover, tissue markers of damage were not collected and could also enrich the results. Finally, muscle soreness was only measured $24 \mathrm{~h}$ after exercise. It is known that exercise muscle soreness may continue up to several days after exercise [7]. However, findings of the present investigation add knowledge to the literature and may trigger further investigation on the topic as the effect of pequi oil supplementation on exercise performance is very poorly characterized.

\section{CONCLUSION}

In summary, it could be suggested that pequi oil supplementation has no influence on blood lactate concentration and removal, as well as on rate of perceived exertion and muscle soreness during resistance exercise training. Alternatively, it is possible to suggest that this supplementation strategy has a different time course of adaptations in the context of resistance training if compared to previous studies adopting aerobic exercise.

\section{REFERENCES}

[1] Lima A de, Silva AM de O e, Trindade RA, Torres RP, Mancini-Filho J. Composição química e compostos bioativos presentes na polpa e na amêndoa do pequi (Caryocar brasiliense, Camb.). Rev Bras Frutic. 2008;29:695-8.

[2] Montalvão TM, Miranda-Vilela AL, Grisolia CK, Santos-Neto LL. Anti-inflammatory Effect of Antioxidant Pequi (Caryocar Brasiliense) Oil Capsules and Antioxidant Effect of Vitamin D and Physical Activity on Systemic Lupus Erythematosus Patients. J Rheum Dis Treat. 2016;2:029.

[3] Miranda-Vilela AL, Pereira LCS, Gonçalves CA, Grisolia CK. Pequi fruit (Caryocar brasiliense Camb.) pulp oil reduces exercise-induced inflammatory markers and blood pressure of male and female runners. Nutr Res. 2009;29:850-8.

[4] Miranda-Vilela AL, Akimoto AK, Alves PC, Pereira LC, Gonçalves CA, Klautau-Guimarães MN, et al. Dietary carotenoid-rich pequi oil reduces plasma lipid peroxidation and DNA damage in runners and evidence for an association with MnSOD genetic variant -Val9Ala. Genet Mol Res. 2009;8:1481-95.

[5] Baechle T, Earle R. Essentials of Strength Training and Conditioning. Third edit. National Strength and Conditioning Association; 2008.

[6] Robertson RJ, Goss FL, Rutkowski J, Lenz B, Dixon C, Timmer J, et al. Concurrent validation of the OMNI perceived exertion scale for resistance exercise. Med Sci Sports Exerc. 2003;35:333-41.

[7] Lau WY, Muthalib M, Nosaka K. Visual analog scale and pressure pain threshold for delayed onset muscle soreness assessment. J Musculoskelet Pain. 2013;21:320-6.

[8] Schoenfeld BJ. Does Exercise-Induced Muscle Damage Play a Role in Skeletal Muscle Hypertrophy? J Strength Cond Res. 2012;26:1441-1453. 
[9] Padilha CS, Ribeiro AS, Fleck SJ, Nascimento MA, Pina FLC, Okino AM, et al. Effect of resistance training with different frequencies and detraining on muscular strength and oxidative stress biomarkers in older women. Age (Omaha). 2015;37.

[10] Ji LL, Kang C, Zhang Y. Exercise-induced hormesis and skeletal muscle health. Free Radic Biol Med. 2016;98:113-22.

Citation: Maurilio T. Dutra, Mateus M. Leite, et.al. " Supplementation with an Antioxidant Rich Oil Does Not Influence Blood Lactate, Rate of Perceived Exertion and Muscle Soreness after Resistance Exercise" International Journal of Sports and Physical Education (IJSPE), vol 5, no. 4, 2019, pp. 01-04. doi: http://dx.doi. org/10.20431/2454-6380.0504001.

Copyright: (C) 2019 Authors. This is an open-access article distributed under the terms of the Creative Commons Attribution License, which permits unrestricted use, distribution, and reproduction in any medium, provided the original author and source are credited. 